\title{
FOCUS EDITORIAL
}

\section{Focus on infection and sepsis 2017}

\author{
Ignacio Martin-Loeches ${ }^{1,2^{*}}$ (D) Jose Garnacho-Montero ${ }^{3,4}$ and Saad Nseir ${ }^{5,6}$
}

(c) 2017 Springer-Verlag Berlin Heidelberg and ESICM

\section{Introduction}

Management of severe infections and sepsis in intensive care units (ICU) represents one of the most common and complex problems in daily clinical practice. Year by year, new studies are helping to improve physicians' management and this manuscript aims to summarize the most relevant works published during 2015-2016 on these difficult areas of knowledge (Table 1).

\section{Surviving Sepsis Campaign controversies}

Probably, one of the most important landmarks in 2016 was the publication of the new edition of the Surviving Sepsis Campaign guidelines [1]. Not all is done and new data will be incorporated in further editions. For instance, in this edition, it is recommended to give a minimum of $30 \mathrm{~mL} / \mathrm{kg}$ of crystalloid solutions within the first $3 \mathrm{~h}$. Interestingly, a recent study found [2] that less fluids were administered to patients with severe sepsis and septic shock in the USA during the first ICU day than recommended by the Surviving Sepsis Campaign guidelines, and this was associated with an increased mortality of $2.3 \%$ per liter of fluid administered above 5 L. Hjortrup et al. [3] randomized 151 adult patients with septic shock in Scandinavia and found that in patients assigned to fluid restriction (fluid boluses only if severe hypoperfusion was detected), fluid volumes at day 5 and during ICU stay were lower than in the standard care group by more than $1 \mathrm{~L}$ with no differences in outcome. The trial was a feasibility trial that actually suggested benefit with fluid restriction but was not powered to address patientcentered outcomes. Following the same idea of "less is more", Rygard et al. [4] reported that a lower hemoglobin threshold for transfusion was associated with neither higher long-term mortality (1 year after randomization)

\footnotetext{
*Correspondence: drmartinloeches@gmail.com

${ }^{1}$ Multidisciplinary Intensive Care Research Organization (MICRO),

Department of Intensive Care Medicine, St. James's Hospital, James's St,

Ushers, Dublin 8 D08 NHY1, Ireland

Full author information is available at the end of the article
}

rates in patients with sepsis nor a worse health-related quality of life (HRQoL).

\section{"Area of need" population studies in sepsis}

Intensive Care Medicine published several special papers in 2016 focused on sepsis management in two types of populations that are commonly not addressed widely: resource-limited settings and the pediatric population. Pediatric populations will benefit from the recently published consensus documents for refractory septic shock in children that included a clinical case-based Delphi survey involving 114 pediatric intensivists [5]. Regarding resource-limited settings, recommendations were published by a multidisciplinary group of experts from different geographic areas who agreed that there is scarce evidence for the management of pediatric and adult sepsis in resource-limited settings [6]. Further efforts should be made from scientific societies to adequately provide resources for this population. A worldwide study demonstrated that gross national income (GNI) was a major determinant of time to death in hospital in ICU patients [7]. Not only GNI but also age (older patients), type of population (surgical), and infection increased the duration of hospital stay prior to death in critically ill patients.

\section{Quick sequential organ failure assessment (qSOFA)-65?}

Studies of sepsis have shown an exponential increase in the population-based incidence of sepsis with age, followed closely by an increased mortality [8]. New sepsis definitions (Sepsis 3.0) were launched in 2016 [9] and have generated some controversy [10]. As communityacquired pneumonia (CAP) is the most common cause of sepsis, Kolditz et al. [11] performed a multicenter validation of the qSOFA score (also known as quickSOFA) in patients with CAP. qSOFA uses three criteria, assigning one point for low blood pressure (SBP $\leq 100 \mathrm{mmHg}$ ), high respiratory rate $(\geq 22$ breaths per $\min )$, or altered mentation (Glasgow coma scale $<15$ ). The authors

\section{Springer}


Table 1 Selected recent findings on infection and sepsis in the critically ill patient

2017 Surviving Sepsis Campaign controversies
Critically ill patients frequently not receiving the recommended quantity of fluids during the first $24 \mathrm{~h}$ of sepsis or septic shock, mortality increased in
patients with severe sepsis receiving $<5$ L of fluids
Lower hemoglobin levels not associated with higher mortality or worse quality of life at 1 year after randomization
"Area of need" population studies in sepsis
Refractory septic shock in pediatric population
Sepsis in resource-limited settings
qSOFA-65?
qSOFA accurate in patients with community-acquired pneumonia
Older patients with influenza prone to higher rates of bacterial co-infection, and higher mortality rates
ICU-acquired infections
Duration of mechanical ventilation, but not antibiotics, associated with changes in lung microbiome
Highly heterogeneous patterns of intestinal microbiota in both septic and non-septic ICU patients
Treatment with probiotics effective and safe to prevent VAP
De-escalation in ICU patients feasible and associated with better outcomes

qSOFA quick sequential organ failure assessment, VAP ventilator-associated pneumonia, MDR multidrug-resistant bacteria, ICU intensive care unit

compared its accuracy to predict disease course to the CRB-65 (confusion, respiratory rate $\geq 30 / \mathrm{min}$, systolic blood pressure $<90 \mathrm{mmHg}$ or diastolic blood pressure $\leq 60 \mathrm{mmHg}$, age $\geq 65$ years) score. qSOFA and $\mathrm{CRB}(-65)$ score do share the same items except age, and the authors found that qSOFA was similar to CRB $(-65)$, with a slightly higher sensitivity and lower specificity. On the basis of their findings, age ( $>65$ years) might be applied as an additional criterion in both scores for optimal low-risk prediction. In a recent observational multicenter study with almost 3000 patients with severe CAP, older patients more often had co-infection when infected by influenza, and co-infection was independently associated with higher mortality [12]. More appropriate triage (resource limitation enforced decisions), admission decisions based on shared decision-making, and improved prediction models should be incorporated in aging populations [13].

\section{ICU-acquired infections}

Nosocomial infections play a major role in the development of sepsis, and ventilator-associated pneumonia (VAP) remains the most common infection in ICU [14]. A recent manuscript by Zakharkina et al. found that duration of mechanical ventilation, but not antibiotic administration, was associated with changes in the respiratory microbiome [15]. Recent studies reported that despite previous evidence [16], highly heterogeneous patterns of intestinal microbiota existed in both septic and non-septic critically ill patients. This might shed light on our understanding of the conflicting results with the effect of probiotics on the incidence of VAP in critically ill patients. In an open-label, multicenter randomized controlled trial involving 235 critically ill adult patients, therapy with the probiotic bacteria Bacillus subtilis and Enterococcus faecalis were found to be effective and safe for preventing VAP and the acquisition of multidrugresistant pathogen (MDR) colonization [17].

Antibiotic stewardship programs have been found to be effective in ICU settings to face the ongoing problem of bacterial resistance and acquisition of MDR [18]. Recently, the World Health Organization, US Centers for Disease Control and Prevention (CDC), European Centre for Disease Prevention and Control, European Medicines Agency, Institute of Medicine, World Economic Forum, and the US Presidential Advisory Council on Science and Technology asked for action to take in this mater [19]. A recent pooled individual data analysis of prospective studies of de-escalation in critically ill patients with sepsis found that while SOFA score and aging were both factors independently associated with mortality, de-escalation was independently associated with a better outcome in the adjusted multivariate analysis [20]. Formal antibiotic stewardship programs are essential to help in reducing either unnecessary or inappropriate antibiotic prescription and subsequently to avoid a rise in antimicrobial resistance.

\section{Concluding remarks}

Mortality and morbidity associated with sepsis remain unacceptably high. Detection of patients in their early stages of the infection is crucial to diminish the high mortality rate associated with sepsis. Further studies are warranted to determine the optimal targets for resuscitation and the best antimicrobial management especially when MDR pathogens are involved. 


\section{Author details}

${ }^{1}$ Multidisciplinary Intensive Care Research Organization (MICRO), Department of Intensive Care Medicine, St. James's Hospital, James's St, Ushers, Dublin 8 D08 NHY1, Ireland. ${ }^{2}$ Department of Clinical Medicine, Trinity College, Welcome Trust-HRB Clinical Research Facility, St James Hospital, Dublin, Ireland. ${ }^{3}$ Unidad Clínica de Cuidados Intensivos, Hospital Universitario Virgen Macarena, Seville, Spain. ${ }^{4}$ Institute of Biomedicine of Seville, IBiS/CSIC/University of Sevilla, Seville, Spain. ${ }^{5}$ Critical Care Center, CHU Lille, Lille, France.

${ }^{6}$ University of Lille, School of Medicine, Lille, France.

Received: 7 March 2017 Accepted: 30 March 2017 Published online: 4 April 2017

\section{References}

1. Rhodes A, Evans LE, Alhazzani W et al (2017) Surviving Sepsis Campaign: international guidelines for management of sepsis and septic shock: 2016. Intensive Care Med 43:304-377. doi:10.1007/s00134-017-4683-6

2. Marik PE, Linde-Zwirble WT, Bittner EA et al (2017) Fluid administration in severe sepsis and septic shock, patterns and outcomes: an analysis of a large national database. Intensive Care Med. doi:10.1007/ s00134-016-4675-y

3. Hjortrup PB, Haase $\mathrm{N}$, Bundgaard $\mathrm{H}$ et al (2016) Restricting volumes of resuscitation fluid in adults with septic shock after initial management: the CLASSIC randomised, parallel-group, multicentre feasibility trial. Intensive Care Med 42:1695-1705. doi:10.1007/s00134-016-4500-7

4. Rygard SL, Holst LB, Wetterslev J et al (2016) Long-term outcomes in patients with septic shock transfused at a lower versus a higher haemoglobin threshold: the TRISS randomised, multicentre clinical trial. Intensive Care Med 42:1685-1694. doi:10.1007/s00134-016-4437-x

5. Morin L, Ray S, Wilson C et al (2016) Refractory septic shock in children: a European Society of Paediatric and Neonatal Intensive Care definition. Intensive Care Med 42:1948-1957. doi:10.1007/s00134-016-4574-2

6. Thwaites CL, Lundeg G, Dondorp AM (2016) Infection management in patients with sepsis and septic shock in resource-limited settings. Intensive Care Med 42:2117-2118. doi:10.1007/s00134-016-4547-5

7. Martin-Loeches I, Wunderink RG, Nanchal R et al (2016) Determinants of time to death in hospital in critically ill patients around the world. Intensive Care Med 42:1454-1460. doi:10.1007/s00134-016-4479-0

8. Yebenes JC, Ruiz-Rodriguez JC, Ferrer R et al (2017) Epidemiology of sepsis in Catalonia: analysis of incidence and outcomes in a European setting. Ann Intensive Care 7:19. doi:10.1186/s13613-017-0241-1
9. Singer M, Deutschman CS, Seymour CW et al (2016) The third international consensus definitions for sepsis and septic shock (Sepsis-3). JAMA 315:801-810. doi:10.1001/jama.2016.0287

10. Rodriguez A, Martin-Loeches I, Yebenes JC (2016) New definition of sepsis and septic shock: what does it give us? Med Intensiva. doi:10.1016/j. medin.2016.03.008

11. Kolditz M, Scherag A, Rohde G et al (2016) Comparison of the qSOFA and CRB-65 for risk prediction in patients with community-acquired pneumonia. Intensive Care Med 42:2108-2110. doi:10.1007/s00134-016-4517-y

12. Martin-Loeches I, Schultz JM, Vincent J-L et al (2016) Increased incidence of co-infection in critically ill patients with influenza. Intensive Care Med. doi:10.1007/s00134-016-4578-y

13. Flaatten $\mathrm{H}$, de Lange DW, Artigas A et al (2017) The status of intensive care medicine research and a future agenda for very old patients in the ICU. Intensive Care Med. doi:10.1007/s00134-017-4718-Z

14. Fan Y, Gao F, Wu Y et al (2016) Does ventilator-associated event surveillance detect ventilator-associated pneumonia in intensive care units? A systematic review and meta-analysis. Crit Care 20:338. doi:10.1186/ s13054-016-1506-Z

15. Zakharkina T, Martin-Loeches I, Matamoros S et al (2017) The dynamics of the pulmonary microbiome during mechanical ventilation in the intensive care unit and the association with occurrence of pneumonia. Thorax. doi:10.1136/thoraxjnl-2016-209158

16. Dickson RP (2016) The microbiome and critical illness. Lancet Respir Med 4:59-72. doi:10.1016/S2213-2600(15)00427-0

17. Zeng J, Wang C-T, Zhang F-S et al (2016) Effect of probiotics on the incidence of ventilator-associated pneumonia in critically ill patients: a randomized controlled multicenter trial. Intensive Care Med 42:1018-1028. doi:10.1007/s00134-016-4303-x

18. Zilahi G, Artigas A, Martin-Loeches I (2016) What's new in multidrugresistant pathogens in the ICU? Ann Intensive Care 6:96. doi:10.1186/ s13613-016-0199-4

19. Spellberg B, Srinivasan A, Chambers HF (2016) New societal approaches to empowering antibiotic stewardship. JAMA 315:1229-1230. doi:10.1001/jama.2016.1346

20. Gutierrez-Pizarraya A, Leone M, Garnacho-Montero J et al (2017) Collaborative approach of individual participant data of prospective studies of de-escalation in non-immunosuppressed critically ill patients with sepsis. Expert Rev Clin Pharmacol 10:457-465. doi:10.1080/17512433.2017.1293 520 